\title{
Research on Values Education
}

\author{
Yafei Wang \\ School of Humanities, Economics and Law \\ Northwestern Polytechnical University \\ Xi'an, China
}

\begin{abstract}
Values, being the core of culture, is dominant in personal socialization. In China, the definite concept, theory and method of values education haven't formed yet though it has been widely concerned and comprehended. This is a problem eagerly needs solving in values area. As schema theory is applied to values education at the aspect of educatees, it offers a new alternative for educators.
\end{abstract}

Keywords—values; values education; schema theory

\section{INTRODUCTION}

An increasing number of countries and regions realize civic values's great impact in social development with a global trend of values diversity and, therefore, values has become an issue needed studying in philosophy, sociology, psychic mental philosophy as well as pedagogy. Meanwhile, the globalization of economy and trade brings a culture globalization simultaneously. Hence, civic values are affected by different culture and shows a tendency towards disperse interest. Scholars find out for sure that, under this circumstance, if we want to maintain social stability, promote social development while preserve national characteristic, civic values needs correctly guided. And this is the terminal aim of values education.

\section{VALUES AND VALUES EDUCATION}

The definition of values varies from different subjects and different aspects. In philosophy, it stresses out that values exists in the relationship between subject and object. Values is the standard system for people themselves to make assessment on objects' significance and effectiveness, also considered as a core factor of pushing and guiding subjects to make decisions and take actions. In sociology, sociologists would explain values in the angle of cultural function. Parsons, a American sociologist, regarded values as "a factor of well-accepted symbolic system(cultural system) and the standard of choices, behavior and goals in society." And from the angle of psychic mental philosophy, established concept of values is closely connected to personal behavior but not a simply metaphysical proposition. Valerie A. Briithwaite and William A. Scott's point of view was that, "Values is a criterion deep into the human mind, the one which determines the future behavior and provides explanation of the past." While Rokeach insisted values is just a ordinary faith with motive function, not only in evaluation but also a social phenomenon. Based on research for many year, Shalom $H$. Schwartz advanced values is a desirable goal beyond the situation taking effect in a man's life and his survival in society. Halstead J. Mark thought people use the word, values, to present their principles, beliefs and a standard of adjusting what is good and worthy.

Now in China, though a lot of research on values can be found, the concept and teaching method of specific values education haven't formed yet and there is no united, clear educational system for values。 Values education is mostly included in moral education or moral character education. Scholars in China consider that values education can be divided into the theory of values education, values cultivation, values psychology guidance and values activities adjustment, among which the ideal and faith of values is the hard-core one. But to the western scholars, values education is a complicated concept hard to precisely define or to find a well-accepted explanation. To some extend, values education is usually connected with the education of spirit, morality, cultural development, personality, virtue, attitude development and personal quality. Majority of countries attach great importance of values education but barely set up reluctant courses. Values education is taken as a reverse subject in the education of nationality, morality and religion. In a broad way, values education including well-accepted values like love, equality, freedom, justice, happiness and safety, besides, more emphas is will be put into education in civic values and moral values.

We can't deny that every person owes specific values and each varies from one to another for the reason that the values establishment depends on factors like personal living experience, studying, social statues, interpersonal communication, etc. Especially under the background of information age, values is tend to be more various and diverse. Being together in a social environment, though each one's values varies, there may generate common, well-accepted values influenced by identical cultural atmosphere and tradition. We always definite the most well-accepted values as main-stream values. And dominant values is the one advocated by a country, government or specific ideology, aiming to pursue its legality and development. Simply puts, the terminal goal of values education is to lead individual values to dominant values as possible while remain civic values education, eventually realize the co-existence featuring diverse values led by dominant values.

\section{FEASIBILITY OF VALUES EDUCATION}

The feasibility of values education is quite a complicated problem needs solving, never lacking controversies and emerg ing opinions. But we can divide them into three groups. 


\section{A. Values Is a Free Select Chosen by Individual and Group, But Not Acquired by Implanting and Compelling}

From the development of values education in other countries, we could find this view, emerged in 1960s, brought up by L. Raths, S. Simon and M. harmin, etc, who were the supporters of values clarification. Early-stage opinions in values clarification upheld that teacher, consultant, parent and leader should never attempt to directly lead or slowly implant their values on the youth, otherwise, which would disturb the youth cultivating their own values. What educators need doing is to provide a circumstance or a chance for individual to choose and select.

The psychology foundation of values clarification owes obvious naturalistic tendency, with its essential guideline for theory and practice is "human-centered" and "studentcentered". But it goes for two more specific contents: First, "values education takes for sure that the youth had established traditional values foundation, which means people themselves, with decent, goodness and mercy in their nature, owing the power of personality to understand correctness and mistakes, justice and equality as well as to recognize their emotion, check out different choices eventually make choices responsible for themselves." In fact, Karstade and Mark have already operated specific research on whether students have acquired their values foundation before they go to school and missions for values education at school, etc. And the answer tuned out "Yes". It seems that school plays the two following roles: First, providing values popular in society, such as fair chances and respect for diversity and discrepancy, to help establish and complete students' developing values; Second, making students reflect on their values and applying it. Kagan operated an discussion in acquirement of children early-stage values and he found out children begin their leaning in values at a very precious time, firstly from family then from media, companies, games group and caregivers as well as the communities and organizations they stay in. Research shows that children have developed their sense of morality in the first two years. Otherwise, researchers of values clarification consider that every person will be inevitably exposed to choices in the future, making choices upon various selects, it's better to let them figure this out in school than to be overwhelm in the face of reality, which is beneficial for students' future development.

\section{B. Values Is Mainly Acquired by Education}

This view emerged after the spring up of values clarification in $60 \mathrm{~s}$ in western countries and personality quality education in 80s.In China, traditional moral education or general moral education both shows positive attitudes toward this view. Some supporters concluded values is in common with other science knowledge, which is objectivity and science. Tough values varies in different nationality, culture and ages, the well-accepted values and accessing standard remain the same. And if it makes sense, the view of values is acquired by education will be supported.

In fact, the key evidences for this view is found in practice. We must admit that values education is an object process, whether you like it or not and whether you call it "education" or not, it goes on and makes influence subtly. Krischenbaum, an American human-centered educator, mentioned his practice in his daughter's education, leading him transfer from his proof values clarification to personality education. He mentioned that when he educated his daughter, insisting the idea of "never imp lant our values on them or it will kill child's independence, "but it turns out that he was actually doing this to his daughter in reality. He would said something like "I am glad you share your toy with your friend, "or intentionally got his daughter in touch with certain examples, decided what kind of films were suitable or commented on protagonist's words and behavior when watching TV with daughter, etc. And all these behavior, in fact, were implanting Krischenbaum's values on his daughter.

Another evidence is a proverb from Mark Twin, "When I was a teenager, I can't believe how stupid my father was. But in my adulthood, I am gradually impressed by father's impact, "which means Mark considered his positive values and personality was influenced by his father. So as the family education and school education. Liked another researcher Krischenbaum said, "the step and strategy of values clarification also contains civic values and values education. Simply puts, when we teach students to listen with a respectful attitude, we actually taught them values of respect ; when we taught team members to take other opinion into consideration, we actually taught them to owe values of equality and empathy. Though we doesn't aim to teach values like mentioned above clearly, but they've been part of potential courses. To sum up, it's self-deceiving and nonsense to partially deny the feasibility of values education because everyone in reality may express or accept a different values.

\section{The Comprehensive Viewpoint of Values Education}

When Krischenbaum described his experience, he also mentioned his teaching in Israel leading his proposal from "values clarification" to "personality education. A student brought up a question on his lecture of values clarification 1, "If values acquired by values clarification, how many people would you think will be volunteer to service in army ? "On other occasion, some even questioned his proposal that "If we let the youth to choose their values, they may choose to take drugs." These questions made KRischenbaum realized it was limited for values clarification to partly stress out personal satisfaction when generating values. If we did this, "We may create a Gandhi, or a Hit ler". Values education should both take individual demand, satisfaction and a nation's responsibility and request on civic people, such as cultivate sense of patriotism and spirit of utter devotion is essential to a country. Therefore, Kris tends to in support of a comprehensive educational method. The youth may only remember some of which we implanted on them; they will remember more if we show things by prove proving it ; but, if we teach knowledge by proving it while offer them a opportunity to settle information on their own, they will explain knowledge in their way and remain knowledge for a more long time, influencing their in deep. So it turns out 
effect of comprehensively teaching values is better. Glaser, another researcher considered that teenager's select on values must be based on they've shaped correct values which is born to have but acquire it education. By traditional education, we teach teenagers to distinguish correctness and mistake as well as generate sense of conscious, sympathy and responsibility. These are the foundation for the youth to make correct select on values, otherwise, it's senseless, even harmful to stress out individual values select in antisocial personality group. Tan Chuanbao has already said, each method owes advantages and disadvantages, if we use a comprehensive way to combine them then mission for values education would be completed. As Makarenko said, a educator of the soviet union, the decisive factor to reach our goal is not single educational method but a combination of them.

\section{VALUES EDUCATION IN SCHEMA THEORY}

Schema is firstly brought up by Jean Piaget, a Swiss psychologist, from his proposal of cognitive development. What is "schema"? We can literally consider it a basic model. And because the schema origins from the research on recognition psychology. Since cognitive schema is a cognitive structure, it symbolizes certain concept or organized knowledge about stimulus type. Simply puts, when mentioned "go to school", we all know it means we go to school to acquire a set of knowledge. Meanwhile, we are not only aware the concept of "go to school" but also its exclusive features like : school is a settled place; teacher is the giver of knowledge ; student is the receptor of knowledge and has to finish his studying mission. People will always have a general and common recognition of "go to school", no matter what kind of school you go to. And this the schema we talk about. More specifically, the concept of schema shows its information is stored in a abstract form but not a general geometry with examples. Cognitive psychology divides cognitive process into two types: one is "From top to bottom" which a cognitive process led by theory and another is "From bottom to top" means theory is develop by information. And the theory in "From top to bottom" is schema, means that people analysis, process and accept the messages they receive in cognitive process with schema. "From bottom to top" means the acceptance and analysis of new messages may influence former schema and finally transfer the former one. In fact, when people accept new messages which is not simple or useless, our cognitive process of these messages can't be clearly divided in two types. Most of the time, these tow types works together. New massages will be accepted and analyzed in former schema but then may change by the acceptance of new messages. And a new schema is created. In cognitive psychology, the basic function of schema is considered to combine the former knowledge, making us understand things effectively. According its forms, we can divide schema into prototype and quintessence Prototype is the one that people's cognitive schema have turned into an abstract, fixed form. Quintessence means when people think a message they will concentrate it into a detailed example. And basically schema can be divided into four types: personal schema, self schema, role schema and event schema. To make it simple, these four one is a cognitive schema of people, self, social roles and social events. In people's specific cognition, of course, there is no clear boundary because these cognitive schema connect with each other in most cases.

Based on the definition of recognition psychology, the forming of schema origins from individual's accepting, analysising and sort-out information in order to establish a standard for receiving messages. If we don't limit schema used only in psychological recognition, it also can be applied to values audiovisual education, which is values schema. What we mentioned above, the forming of individual's values origins from living experience, studying, social status and intercommunicate, etc. Which means individual values is in the same with individual values schema while values education is being new information for educatees to accept, analysis and select. Under the guideline of schema theory, educatee, a audience of values education, should firstly analysis educator's living experience, studying, social status and intercommunicate according to schema theory, then, analysising the information of how educator accept and analysis values education. There are three subsystems in the process educatee accept information-dynamical system, cognitive system and regulating system, among which dynamical system is used for selecting and acquire reluctant information about values education ; recognition system is for analysising, filtrating and commenting reluctant information that affects educate; adjustment system is for deciding whether to recognize information in same-values educational system and adjust former schema model. Applying the schema theory to values education should not only respect educator's dominant status and fully analysis educatee's former values schema while, under the condition of educatee's acceptance, give a proper, scientific and targeted values education.

\section{REFERENCES}

[1] Parsons., America,"The Structure of Social Action" [M].Nanjing:Yiling Press,2003,pp.56 .

[2] Halstead, J. Mark, Taylor, Monica J. Learning and Teaching about Values: a review of recent research. Cambridge Journal of Education. Jun 2000, Vol. 30 Issue 2, p169.

[3] Tan Chuanbao,"The Principles of Moral Education in School'[M].Beijing:Science and Education Publishing,pp.144-146,2000.

[4] Li Binxiong,"First Discussion about Values Education "[C].the 21st century values education and culture strategy academic conference paper,2001.

[5] Krischenbaum H. A comprehensive model for values education and moral education. Phi Delta Kappan, Jun 1992, Vol. 73 Issue 10, p771.

[6] Li Deshun, "Axiology - Study on Subjectivity(the third edition)" [M].Beijing:China Renmin University Press,2013.

[7] Zheng Quanquan,"Conception and Behavior of Chinese '[M].T ianjin:Tianjin Peoples Publishing House, 1995. 